\title{
A comparative study on security features of Indian, Canadian and Dubai cheques
}

\begin{abstract}
"Cheque" is one of the most important and common document used for all financial transactions by banks all over the world. Therefore, there is urgency to maintain the security of the cheque. In order to prevent fraud and counterfeiting in cheque, different security features are appended in the cheque, but still there is a chance to improvise. Security features are the vital line of defence against the cheque frauds. The security features present in the cheque consist of the watermarks, logo, Serial number, account number, bank name which are visible under different light sources and instruments. In the present study the security features of modern Indian cheque (Punjab National Bank), Canadian cheque (Canada Trust) and Dubai cheque (Emirates NBD) are examined and compared. Ensuingly studying the security features of three different countries, it can be concluded that in Indian cheque ample numbers of security features are found and minimal security features are found in Canadian cheque, although Dubai cheque has acceptable and exclusive security features.
\end{abstract}

Volume 6 Issue 3 - 2018

\author{
Bhavya Sharma, Aman Sharma, Shipra \\ Rohatgi, Bhuvnesh Yadav \\ Amity School of Applied Sciences, Amity University, India
}

Correspondence: Bhuvnesh Yadav, Assistant Professor, Forensic Sciences, Amity School of Applied Sciences, Amity University, Amity Education Valley, Panchgaon, Manesar Gurugram, Haryana- I224I3, India, Tel 9899402613, Email bhuvneshyadav@gmil.com

Received: June 12, 2018 | Published: June 27, 2018

Keywords: cheque, security features, examination, embedded, comparison, counterfeiting

\section{Introduction}

Cheque is a document that orders the bank to pay a specific amount of money from the holder's account to the person whose details are drafted on the cheque. Cheque is one of the most prevailing documents of the bank whose chances of being counterfeited is maximum, therefore in order to prevent counterfeiting the cheque are being embedded with security features. Cheque is essentially considered as the bill of exchange that is manufactured in order to make money transactions without having cash in hand. ${ }^{1}$ Section 13 of Negotiable Instruments Act, 1881 (Act no. 26 of 1881) of Indian constitution states that a negotiable instrument is a promissory note, bill of exchange or a cheque payable either to payee or to a bearer and Section 6 of this Act exclusively defines a cheque as a bill of exchange drawn on a specified banker, and not expressed to be payable otherwise

Table I Results of comparative study of cheques than on demand. ${ }^{2}$ Cheque is an instrument in writing containing an unconditional order, addressed to a banker, signed by the person who has deposited money with the banker, requiring him to pay on demand a certain sum of money only two or to the order of a certain person or to the bearer of instrument. ${ }^{3}$

\section{Methodology}

\section{Sample collection}

The Cheques from different country, mainly India, Dubai, Canada were collected and the analysis was being performed by using Ultra violet light, microscope and magnifying glass. A detailed examination of the security features embedded in the cheques of different countries was done and the comparison was made along with the area of improvement. The result is depicted in (Table 1) \& (Table 2).

\begin{tabular}{|c|c|c|c|}
\hline Features & Indian cheque & Dubai cheque & Canadian cheque \\
\hline Watermark & $\begin{array}{l}\text { Present (Logo and bank } \\
\text { name) }\end{array}$ & $\begin{array}{l}\text { Present (Registered watermark "S" } \\
\text { negative and "S" positive) }\end{array}$ & Present (Circular patterns) \\
\hline Account Holder's Details & $\begin{array}{l}\text { Present (Name, Account } \\
\text { number) }\end{array}$ & Present (Name, Account number) & Present (Name.Address) \\
\hline Pantograph & Present & NIL & NIL \\
\hline Language & English and Hindi & English and Arabic & English \\
\hline U.V.Visible Features & $\begin{array}{l}\text { Present (Bank logo, } \\
\text { amount column) }\end{array}$ & Present (Tamper evident) & $\begin{array}{l}\text { Present (Date column, Owners Identity, } \\
\text { Memo column, and amount column) }\end{array}$ \\
\hline Unique Printing Ink & $\begin{array}{l}\text { Present ( Bleeding effect } \\
\text { when water is dissolved } \\
\text { with ink) }\end{array}$ & $\begin{array}{l}\text { Present (Thermo chromic ink used } \\
\text { to write the word "Cheque") }\end{array}$ & $\begin{array}{l}\text { Present (Chemical indicators appears } \\
\text { as stained if exposed to common ink } \\
\text { solvents and will be visible under Ultra } \\
\text { Violet light) }\end{array}$ \\
\hline Microscopic Features & Present & Present & Present \\
\hline $\begin{array}{l}\text { Anti Photocopying } \\
\text { Feature }\end{array}$ & Present & Present & $\begin{array}{l}\text { Present ("ORIGINAL DOCUMENT" } \\
\text { text, and patterns that cannot be } \\
\text { photocopied) }\end{array}$ \\
\hline Paper Material Used & Carbon free and UV free & Carbon free and UV free & $\begin{array}{l}\text { Carbon free and UV free with reaction } \\
\text { towards chemical. }\end{array}$ \\
\hline $\begin{array}{l}\text { Security features } \\
\text { description }\end{array}$ & NIL & $\begin{array}{l}\text { Present (Security feature Guidelines } \\
\text { are given on the back side of the } \\
\text { cheque) }\end{array}$ & $\begin{array}{l}\text { Present (Guidelines are given on the } \\
\text { back side of the cheque) }\end{array}$ \\
\hline
\end{tabular}


Table 2 Unique security features in various countries cheques

a) Micro printing, Text and pattern on back side of cheque

\section{Canadian Cheque}

2. Indian Cheque

\section{Dubai Cheque}

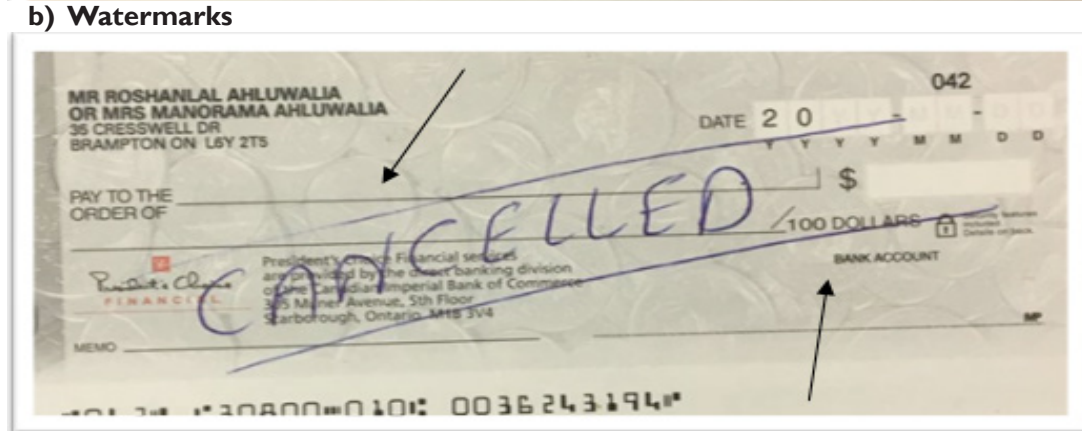

a) Pantograph Box

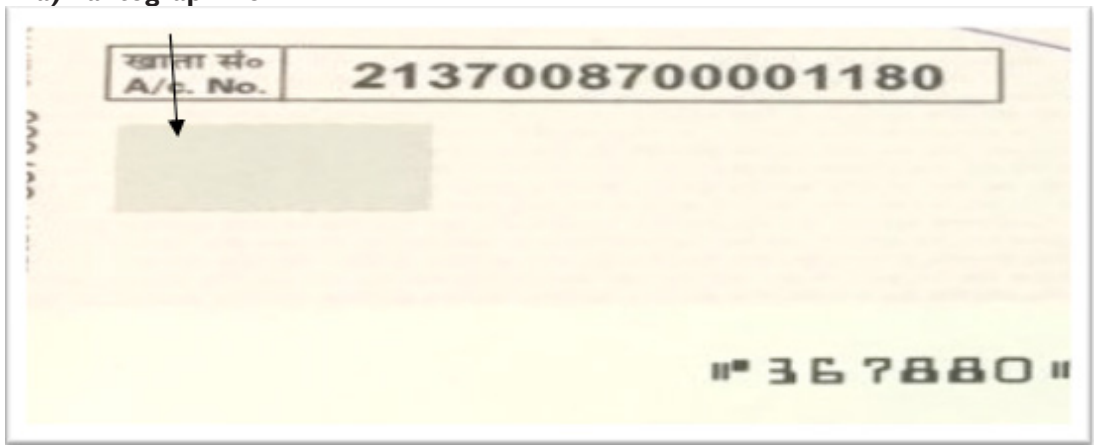

a) Watermarks:

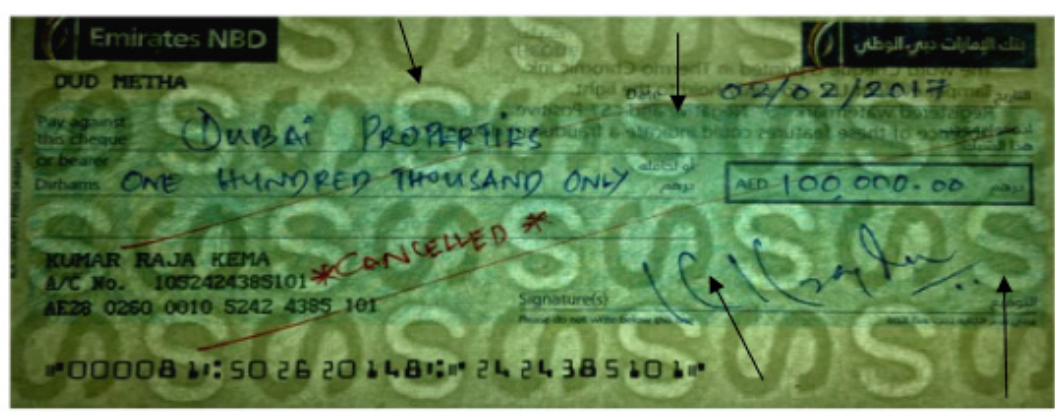

b) Cheque design:

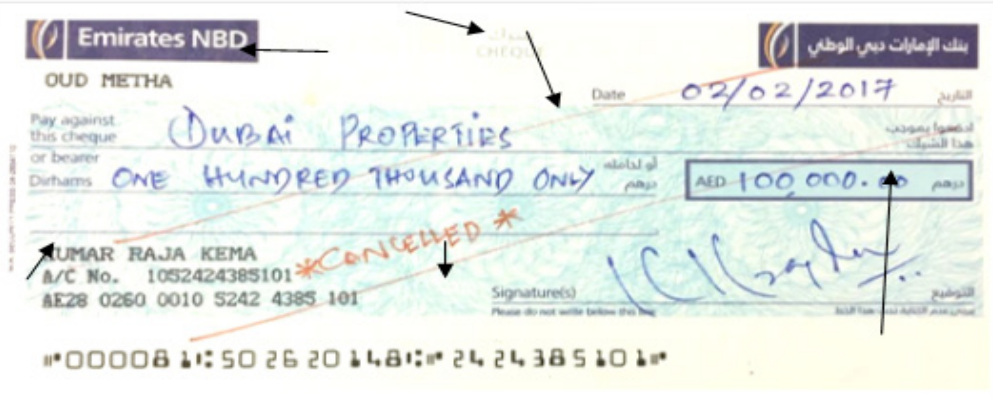

Citation: Sharma B, Sharma A, Rohatgi S, et al. A comparative study on security features of Indian, Canadian and Dubai cheques. Forensic Res Criminol Int J. 20I8;6(3):254-259. DOI: 10.15406/frcii.2018.06.002I2 


\section{C) Thermo chromatic ink:}

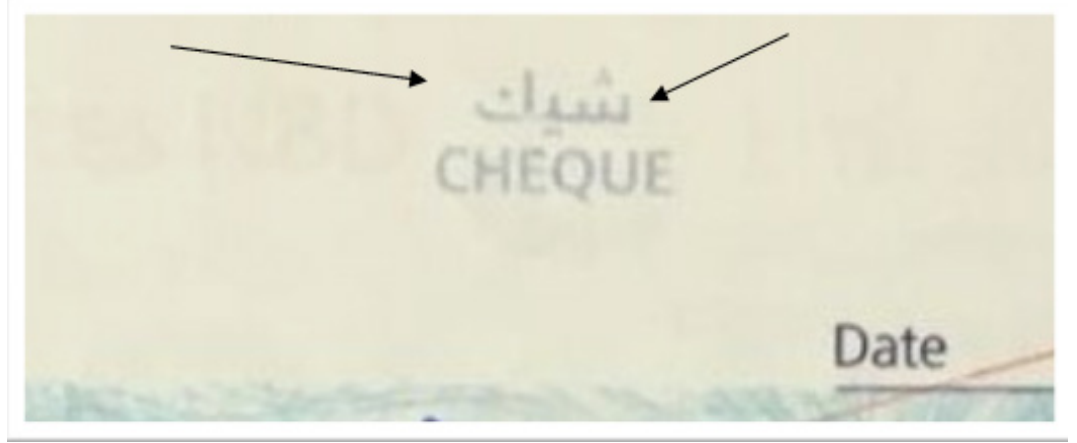

\section{d) Security features information on the backside}

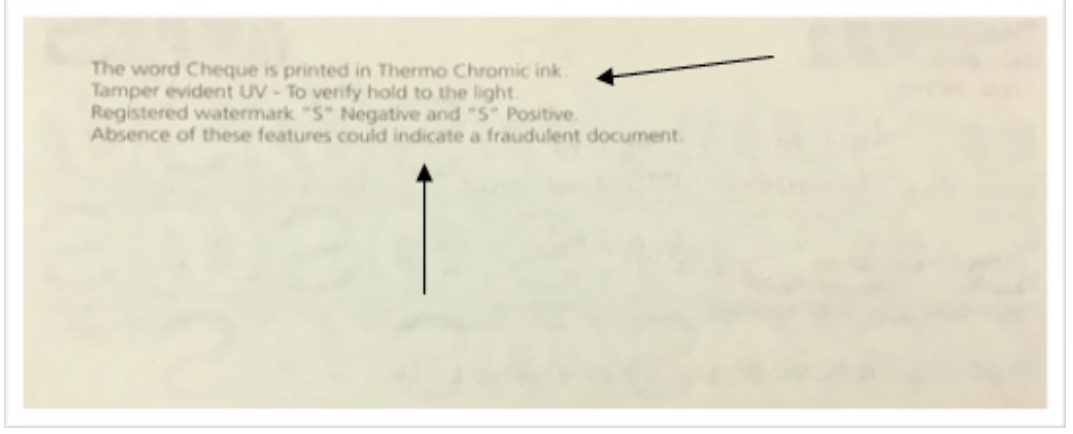

\section{Commonly encoutered security features}

Security features are the features which are embedded in the cheques at the time of manufacturing $\&$ printing which secure it from counterfeiting. The security features make a paper endorse, for example- passport, Pan Card, Voter Id, Aadhar card, currency, cheque etc. So, the size, shape and nature of the security feature are required to be meticulously embedded in the cheque. There are a number of security features in a cheque that can be visible under normal lighting conditions and usually help a layman to identify and find the difference between genuine and fraudulent cheque. The type and amount of security features embedded in a cheque may differ among countries and banks (Figure 1).

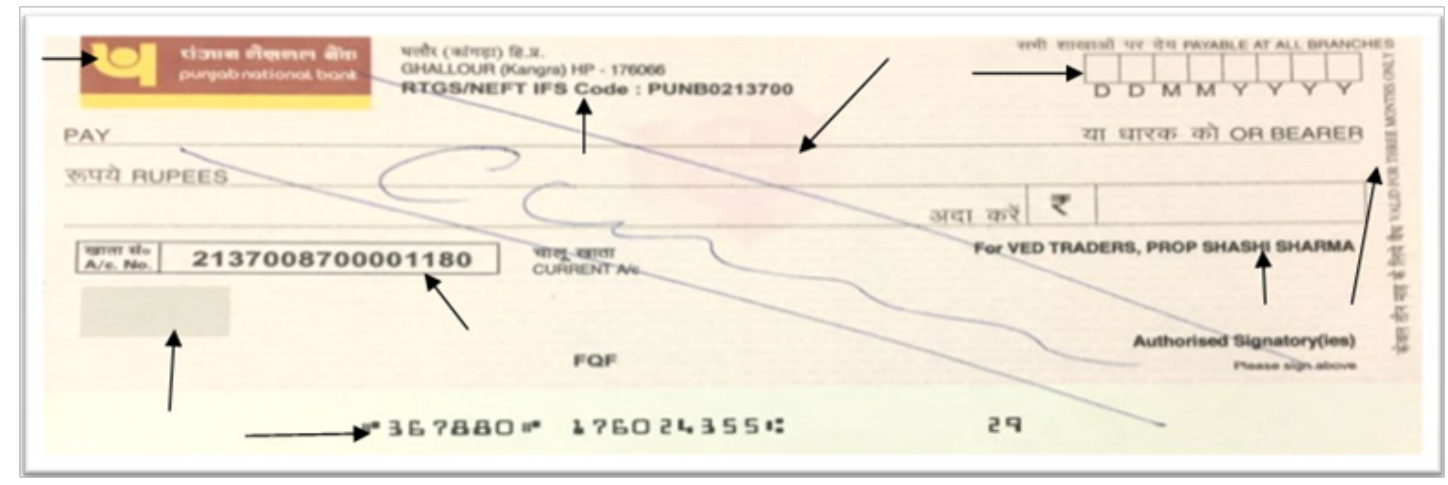

Figure I Showing Indian cheque under normal light.

In general, common security features that imply in a cheque are as follow:

\section{General Features}

Cheque Design: Every bank has its own design, logos and background printing. Every cheque had printed general information about the bank such as bank name, branch address, holograms and bank logo. It generates difficulty for a layman to comprehend between the genuine and fraudulent cheque, if the cheque is designed in a cinch manner it can be easily counterfeited.
Uniform Dimensions: Dimensions play a very significant role in order to secure a cheque. Dimensions of a genuine and a fraudulent cheque can be easily observed. In India, according to RBI (Reserve Bank of India) guidelines, there is a fix length and width of a cheque for almost all the banks in India. The length of a standard cheque is $202 \mathrm{~mm}$ and the width is $92 \mathrm{~mm}$. The length of the white strip for MICR on the bottom of the cheque is $202 \mathrm{~mm}$ and the width is 13 $\mathrm{mm}$. The length of the Amount box is $39 \mathrm{~mm}$ while the width is 8.5 $\mathrm{mm}$. The diagonal length is $220 \mathrm{~mm} .{ }^{4}$ For other countries dimensions may vary accordingly. 
Paper Quality: As per concern of security features in a cheque main concern is to secure the paper otherwise it can be deceit easily. The paper used for manufacturing of Indian cheque is carbon free paper and UV free paper, which means that the paper when observed under the UV light, it would not give florescent appearance ${ }^{[5]}$. In replacement of which, UV visible features are incorporated in paper during the manufacturing process.

Watermarks: According to the previous researches watermarks are considered as one of the best security feature, as they cannot be counterfeited easily. There are variety and different combination of watermarks which can be observed in different bank cheques which are visible under various lights and instruments. During the study of Indian cheque (Punjab National Bank) it was observed that the watermarks were in the form of bank logo or bank name. Where as in Dubai cheque "S" negative and "S" positive watermarks were seen in horizontal and vertical order (Figure 2).

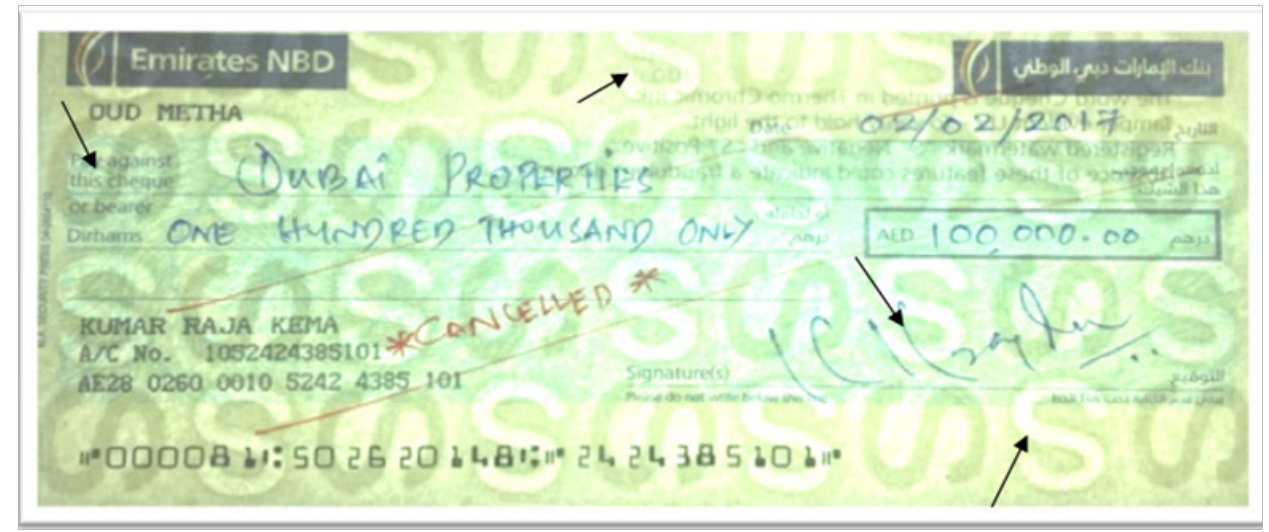

Figure 2 Showing watermarks in Dubai cheque.

Colour System: The colour system differs from the country to country. The bleeding effect is a common phenomenon in Indian cheque that is if water drops over the cheque the ink dissolve in water. ${ }^{5}$ Where as in the Canadian cheque, chemical indicators are used in the paper which can only be visible just under U.V light.

\section{Ultra violet visible features}

Every cheque have U.V. Visible feature, the cheque observed under the U.V light, gives a florescent appearance. The U.V visible features embedded in a cheque vary from bank to bank. The florescent features in cheque can be in the form of bank logo, bank name, Rupee column, micro lettering at the back, amount in words and amount in figures, signature and beneficiary name. These are the most secure features and can be detected easily under U.V light. An apparent difference can be seen between the genuine and the fraudulent cheque when observed under U.V light. In fraudulent cheque the entire paper will turn blue florescent in nature, while in genuine cases it would not give florescent appearance for unify and only specific features will appear as florescent (Figure 3).

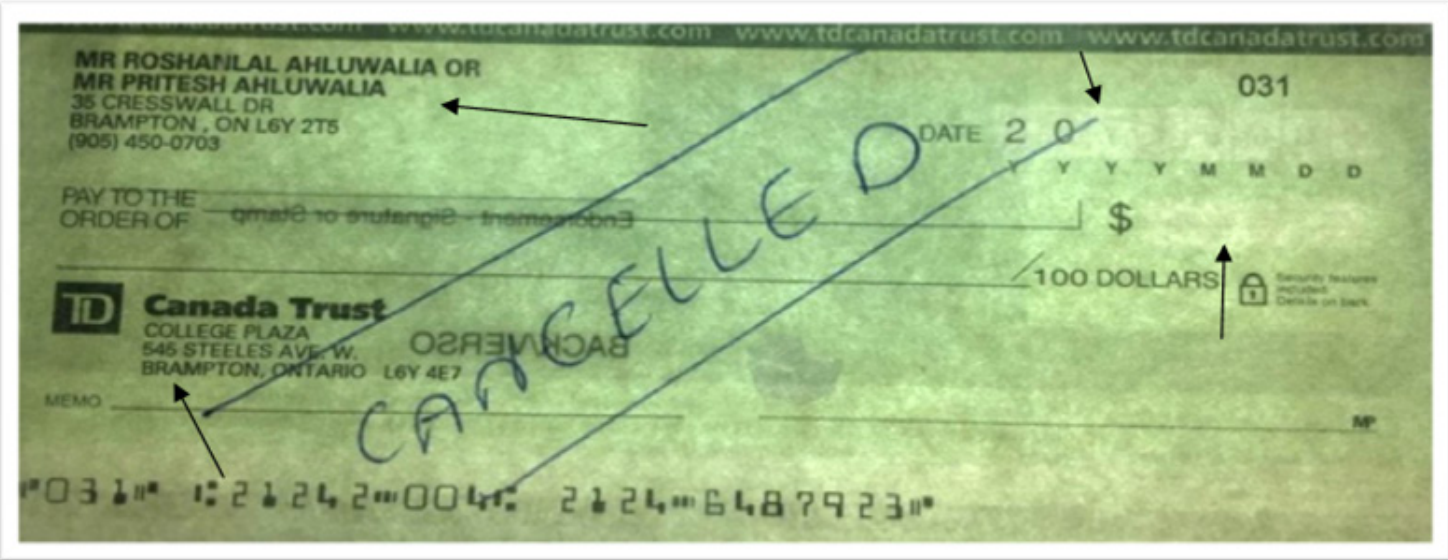

Figure 3 showing florescent features under U.V light in Canadian cheque.

Microscopic features: Modern Indian cheque has microscopic features which are located on entire paper or underneath the date columns, pay column, amount box, and rupee column. ${ }^{5}$ These features can be examined under the microscopes or can be recognized using a magnifying glass. So, if the cheque is photocopied or scanned these micro letters would not be legible. In Canadian cheque micro printing is present on the back side which is depicted as "ORIGINAL DOCUMENT" and cannot be displayed on photocopied cheque. 
Void Pantograph: A rectangular box present on the cheque downwards to the account number column. This feature is only present in Indian cheque amid all. There is a unique arrangement of lines in the box which is based on the principle of steganography. In broad terms, if the genuine cheque will be photocopied then a cheque will show "VOID" or "COPIED" instead of a black space for filling of amount ${ }^{[5]}$. The preeminent impediment is that, it would not accord for laser machines with high ink jet quality, scanning machines or any other high quality machine, so in such cases no such marks of the void or copy will exist (Figure 4).

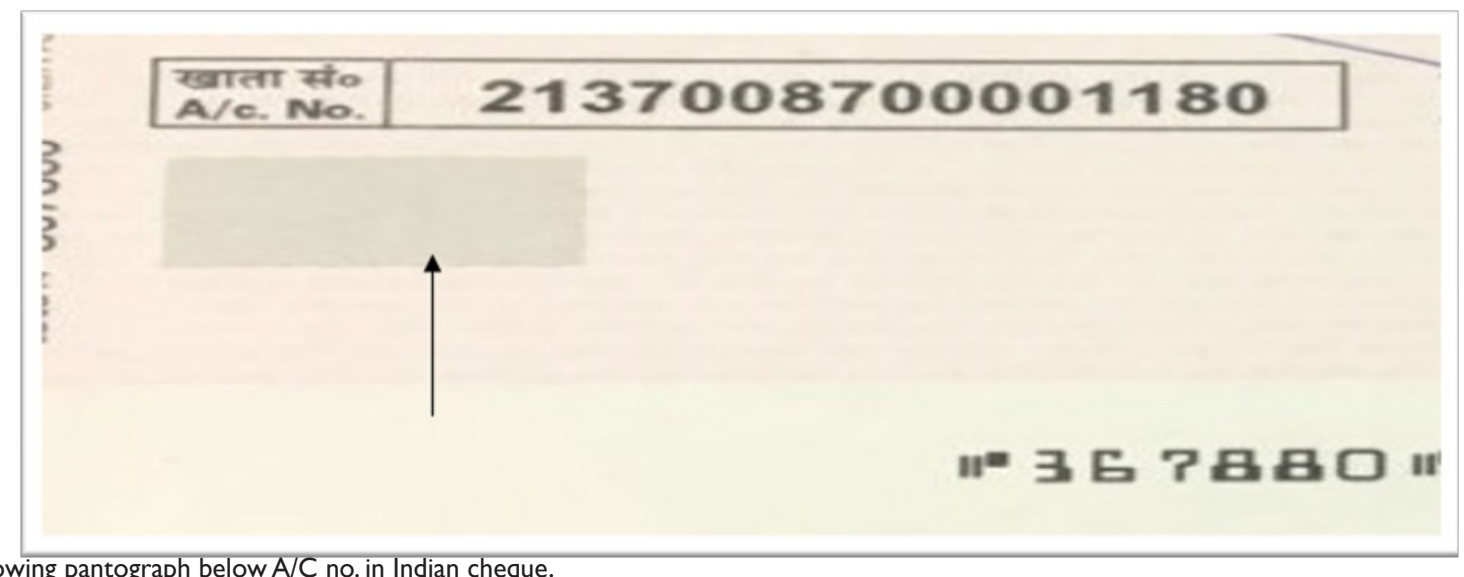

Figure 4 Showing pantograph below A/C no. in Indian cheque.

\section{Observations and result}

In the present study, it is observed that the cheques are being highly secured with the help of various security features but still the chances of counterfeiting are possible. There are various security features present in the cheque of various countries. The most common features encountered in the cheques were water watermarks, colour system, U.V visible features, microscopic printing. After the detail analysis of Indian, Dubai and Canadian cheques bear anti photocopying features in them. But in the term of size Dubai and Canadian cheque were small as compared to Indian cheque. In India, security features in a cheque are issued by RBI, which remains the same for all the government and the private banks of India. Also, some of the security features can be contrasted among various banks; that may include watermarks, U.V features, etc (Figure 5). In Canada, CAP (Canadian Payments Association) issues the security features of the cheque. The security features are different from the business and the personal cheque and have their own specifications. ${ }^{6}$ In this presented study cheque used for examination is of Canada trust (TD) bank (Figure 6). In Dubai, security features of the cheque are issued by the Central bank of UAE. In this cheque register " $S$ " negative and "S" positive water marks are embedded which is the most exclusive feature amid all (Figure 7).

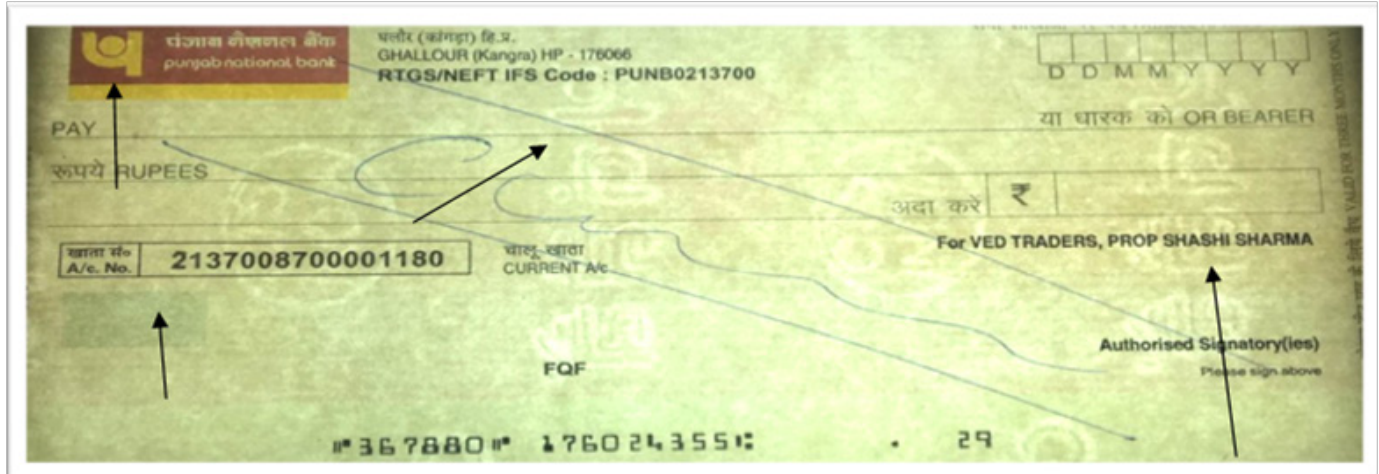

Figure 5 showing Indian cheque under U.V. light.

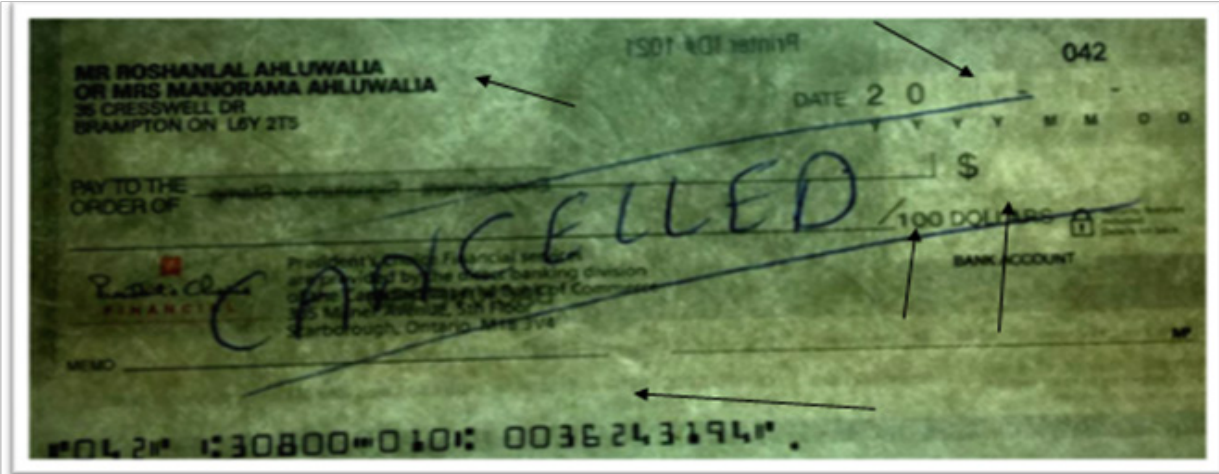

Figure 6 Showing Canadian cheque under U.V light. 


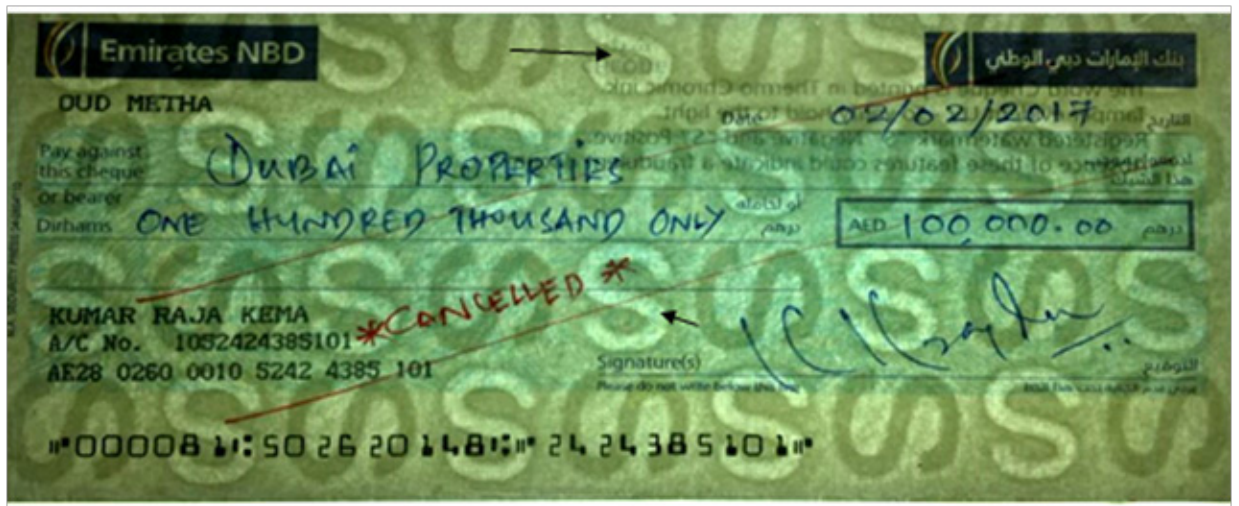

Figure 7 Showing Dubai cheque under U.V. light.

\section{Conclusion}

From the present study it can be concluded that Indian cheque have a maximal number of security features. The solitary feature that Indian cheques have is a pantograph image which is present underneath the account number column. Due to this feature "VOID" or "COPIED" will appear in the pantograph box, if the Indian cheque is photocopied using any regular photocopy machine. But the result would not be same if laser printers or scanners are used. So, there is a chance of incorporation more securely advance features which needs to be emphasized by the government of India for better and safe transactions in future. We would like to propose certain security features such as hologram, Micro printing, patterns on the back side of the cheque which cannot be photocopied by any mode, security threads; security features guideline on the back side of the cheque, advancement in watermark patterns (introducing negative/positive watermarks) and abating the size of the cheque. The Cheque books can also be partitioned on the basis of money to be transacted i.e. separate cheque book can be issued for the colossal transactions and transactions less than 1 lakh. In the further study, we would be focusing upon the production and embedding of proposed security features to provide authenticity, intact and secure transactions.

\section{Acknowledgments}

None.

\section{Conflict of interest}

Author declares that there is no conflict of interest.

\section{References}

1. Sharma V. Information Technology Law and Practice. Universal Law Publishing. 2005.

2. Sople VV. Legal Aspects of Marketing in India. New Age International. 2007.

3. Ellinger EP. Travellers' cheques and the law. The University of Toronto Law Journal. 1969;19(2):132-156.

4. Ketan P, Navjot K, Manish M. Study of Genuine and Forged Indian Bank Cheques by Using Video Spectral Comparator-40. International Journal of Innovative Science, Engineering \& Technology. 2017;4(1):139.

5. Moinuddin M, Prajakta H. Indian Bank Cheques: Security. Features. PFSI; 2014.

6. Cheque printing standards. In RBC royal bank site. 2017.

7. Jose CL. New security features for cheques. In Emirates 24 site. 2009. 